\title{
Plantas medicinais de uso tradicional na região sul paraense: um estudo etnobotânico
}

\author{
Medicinal plants for traditional use in the south of Pará: an ethnobotanical study \\ Plantas medicinales de uso tradicional en el sur de Pará: un estudio etnobotánico
}

Recebido: 19/09/2021 | Revisado: 27/09/2021 | Aceito: 30/09/2021 | Publicado: 02/10/2021

\author{
Maria Viana Ferreira \\ ORCID: https://orcid.org/0000-0002-0617-2853 \\ Faculdade Integrada Carajás, Brasil \\ E-mail: vianamariahta@outlook.com \\ Lucélia Paz Lebuino \\ ORCID: https://orcid.org/0000-0003-4736-9182 \\ Faculdade Integrada Carajás, Brasil \\ E-mail: lucelialebuino@gmail.com \\ Jânio Sousa Santos \\ ORCID: https://orcid.org/0000-0003-2180-1109 \\ Faculdade Integrada Carajás, Brasil \\ E-mail: santosjs.food@gmail.com
}

\begin{abstract}
Resumo
As plantas são parte integrante da cultura da civilização, usadas como fonte alimentar ou finalidade terapêutica. Com o passar do tempo as propriedades curativas dos vegetais foram sendo cada vez mais descobertas e utilizadas. Um saber cultural e valioso passado de geração para geração. Entretanto, no Brasil, as pesquisas que avaliam o grau de utilização das plantas como medicamentos e sua inclusão na cultura popular são escassas, apesar de existir grande tradição de seu uso em vários biomas. Frente a isto, a presente pesquisa analisou por meio de questionário, quais as espécies de plantas medicinais mais utilizadas na medicina tradicional local e qual sua finalidade terapêutica. Foi realizada uma pesquisa qualitativa do tipo exploratória/descritiva com os habitantes da zona urbana da cidade de Redenção localizada na região sul Paraense, onde foram realizadas entrevistas, utilizando-se um questionário como instrumento da pesquisa. Constatou-se que os entrevistados, de modo geral, afirmam fazer uso das espécies medicinais e que a em sua maioria o fazem da forma correta. Observou-se, também que a principal forma de transmissão de conhecimento é por meio da família. Nesta pesquisa ficou evidente, que as plantas mais utilizadas pelos moradores desta cidade são Capim cidreira, Boldo-do-chile ou boldo-verdadeiro, Erva-cidreira, Hortelã e Matruz ou Erva de Santa Maria, sendo as folhas a parte mais utilizada e o chá como principal meio de preparo.
\end{abstract}

Palavras-chave: Plantas medicinais; Fitoterapia; Medicina popular; Regionalidade.

\begin{abstract}
Plants are an integral part of the culture of civilization, used as a food source or therapeutic purpose. Over time, the healing properties of vegetables were increasingly discovered and used. A cultural and valuable knowledge passed from generation to generation. However, in Brazil, research that assesses the degree of use of plants as medicines and their inclusion in popular culture are scarce, although there is a great tradition of their use in several biomes. In view of this, this research analyzed, through a questionnaire, which species of medicinal plants are most used in local traditional medicine and what their therapeutic purpose is. Qualitative exploratory/descriptive research was carried out with the inhabitants of the urban area of the city of Redenção located in the southern region of Pará, where interviews were conducted, using a questionnaire as a research instrument. It was found that respondents, in general, claim to make use of medicinal species and that most do so correctly. It was also observed that the main form of knowledge transmission is through the family. In this research, it was evident that the plants most used by the residents of this city are Lemongrass, Boldo-do-Chile or Boldo-Verdadeiro, Lemongrass, Mint and Matruz or Erva de Santa Maria, the leaves are the most used part and the tea as the main means of preparation.
\end{abstract}

Keywords: Medicinal plants; Phytotherapy; Folk medicine; Regionality.

\section{Resumen}

Las plantas son una parte integral de la cultura de la civilización, utilizadas como fuente de alimento o con fines terapéuticos. Con el tiempo, las propiedades curativas de las verduras se descubrieron y utilizaron cada vez más. Un conocimiento cultural y valioso que se transmite de generación en generación. Sin embargo, en Brasil, las investigaciones que evalúan el grado de uso de las plantas como medicamentos y su inclusión en la cultura popular son escasas, a pesar de la gran tradición de su uso en varios biomas. Por ello, esta investigación analizó, mediante un cuestionario, qué especies de plantas medicinales son más utilizadas en la medicina tradicional local y cuál es su finalidad terapéutica. Se realizó una investigación cualitativa exploratoria/descriptiva con los habitantes del área 
urbana de la ciudad de Redenção ubicada en la región sur de Pará, donde se realizaron entrevistas, utilizando un cuestionario como instrumento de investigación. Se constató que los encuestados, en general, afirman hacer uso de especies medicinales y que la mayoría lo hace correctamente. También se observó que la principal forma de transmisión de conocimientos es a través de la familia. En esta investigación se evidenció que las plantas más utilizadas por los habitantes de esta ciudad son Limoncillo, Boldo-do-Chile o Boldo-Verdadeiro, Limoncillo, Menta y Matruz o Santa María Erva, siendo las hojas la parte más utilizada y la más utilizadas. el té como principal medio de preparación.

Palabras clave: Plantas medicinales; Fitoterapia; La medicina popular; Regionalidad.

\section{Introdução}

As plantas são parte integrante da cultura da civilização, sendo usadas como fonte alimentar para finalidades terapêuticas e até mesmo em rituais religiosos. O uso de espécies vegetais com fins medicinais surgiu por meio de um método empírico tão antigo quanto a própria humanidade, auxiliando o processo de distinção entre as plantas próprias para o consumo daquelas que apresentavam toxicidade. Dessa maneira, as propriedades intrínsecas das plantas passaram a compor o repertório do conhecimento popular e cultural (Duarte, Martins, Miguel \& Gomes, 2017).

Com o passar do tempo as propriedades curativas dos vegetais foram sendo cada vez mais descobertas e utilizadas. Um saber cultural e valioso passado de geração para geração. Mesmo com todo o avanço advindo da indústria farmacêutica, as plantas medicinais, definidas como aquelas capazes de fornecer princípios ativos que possam agir no funcionamento de órgãos e sistemas. Fazendo com que seja restaurado o equilíbrio orgânico ou a hemostasia nos casos de enfermidades (Souza, Ataliba, Costa \& Farias, 2017)

As substâncias produzidas pelas plantas com finalidade terapêutica são classificadas como metabólitos secundários, que pode ser biossintetizados pela via do ácido chiquímico, precursor de taninos hidrolisáveis, cumarinas, alcalóides derivados dos aminoácidos aromáticos e fenilpropanoides, e podem ser derivados do acetato que são "terpenoides, esteroides, ácidos graxos e triglicerídeos" (Sousa et al., 2017).

A Organização Mundial da Saúde (OMS) afirma que cerca de $85 \%$ das pessoas do mundo fazem uso das plantas medicinais para tratamento de saúde. Mesmo estando a medicina moderna bem desenvolvida na maior parte do mundo, grande parte da população dos países em desenvolvimento depende da medicina tradicional para sua atenção primária. Sendo que $80 \%$ desta população usam práticas tradicionais nos seus cuidados básicos de saúde, e aproximadamente $85 \%$ da medicina tradicional envolve o uso de extratos de plantas (Gonçalves et al., 2018).

O Brasil é um dos maiores centros de biodiversidade vegetal do planeta por conter variados ambientes e floras especificas, e abrigar centenas de grupos étnicos, que introduziram na cultura popular a utilização de variadas espécies para os mais diversos fins, dentre eles o uso medicinal. Além da assimilação dos conhecimentos indígenas, as contribuições trazidas pelas culturas africanas e europeias representaram papel importante para o surgimento de uma medicina popular rica. Entre as plantas medicinais que tiveram origem na cultura dos diversos grupos indígenas estão a ipeca, o jaborandi, a carqueja, o guaraná, o taiuiá e a erva-de-bugre. Muitas outras foram trazidas pelos europeus, como a hortelã, a camomila, a malva e o funcho. Já pelos africanos, foram trazidas a erva-guiné e o melão-de-São-Caetano (Costa \& Mayworm, 2011).

Entretanto, no Brasil, as pesquisas que avaliam o grau de utilização das plantas como medicamentos e sua inclusão na cultura popular são escassas, apesar de existir grande tradição de seu uso em vários biomas, como na Amazônia, no Cerrado e na Mata Atlântica (Santos \& Trindade, 2017).

Até o momento, não existem dados sobre as plantas empregadas na medicina popular na região Sul Paraense. Frente a isto, a presente pesquisa analisou por meio de questionário, quais as espécies de plantas medicinais mais utilizadas na medicina tradicional local e qual sua finalidade terapêutica. Tornando evidente os conhecimentos provindos de seus habitantes e assim contribuindo para que outros também conheçam suas tradições quanto ao uso das plantas medicinais. 


\section{Metodologia}

\section{Coleta de dados}

Foi realizada uma pesquisa qualitativa do tipo exploratória/descritiva. Optou-se por este método, por considera-lo como o mais adequado para entender os significados, as experiências e as percepções que as pessoas têm sobre um determinado assunto, neste caso, o uso de plantas medicinais no cuidado terapêutico.

A pesquisa foi realizada com os habitantes da cidade de Redenção localizada na região sul Paraense, na qual foram realizadas entrevistas, utilizando um questionário como instrumento da pesquisa. As perguntas foram feitas aos indivíduos nas residências urbanas do município de Redenção.

A coleta de dados ocorreu entre os meses de maio e julho de 2021. Foram aplicados 100 questionários em residências do núcleo urbano da cidade, sendo escolhidas ao acaso, distribuídas em distintos bairros da cidade. Os moradores foram convidados a participar da entrevista, sendo-lhes esclarecidos quanto ao uso dos dados que compõe a mesma e convidados a assinar o termo de consentimento livre esclarecido. Foram convidados moradores de ambos os sexos, dispostos a responder as perguntas com clareza. Utilizou-se como critério de inclusão: ter idade mínima de 18 anos e aceitar fazer parte da pesquisa. Como critério de exclusão: pessoas menores de idade, possuir déficits cognitivos ou de fala que impossibilitem o participante de conseguir responder a entrevista, como por exemplo, Doença de Alzheimer, demências, afasia, entre outros.

O questionário utilizado como ferramenta da pesquisa continha questões abertas e fechadas, e foi aplicado de forma oral (Quadro 1). Conteve perguntas que abordaram a caracterização do público participante, sendo possível assim um levantamento de dados pessoais e socioeconômicos, informações relacionadas aos conhecimentos dos moradores sobre uso de plantas medicinais, as plantas que conhecem, como as obtém, as plantas medicinais que mais utilizam e forma de preparo, e sua finalidade terapêutica.

Quadro 1 - Questionário utilizado na pesquisa.

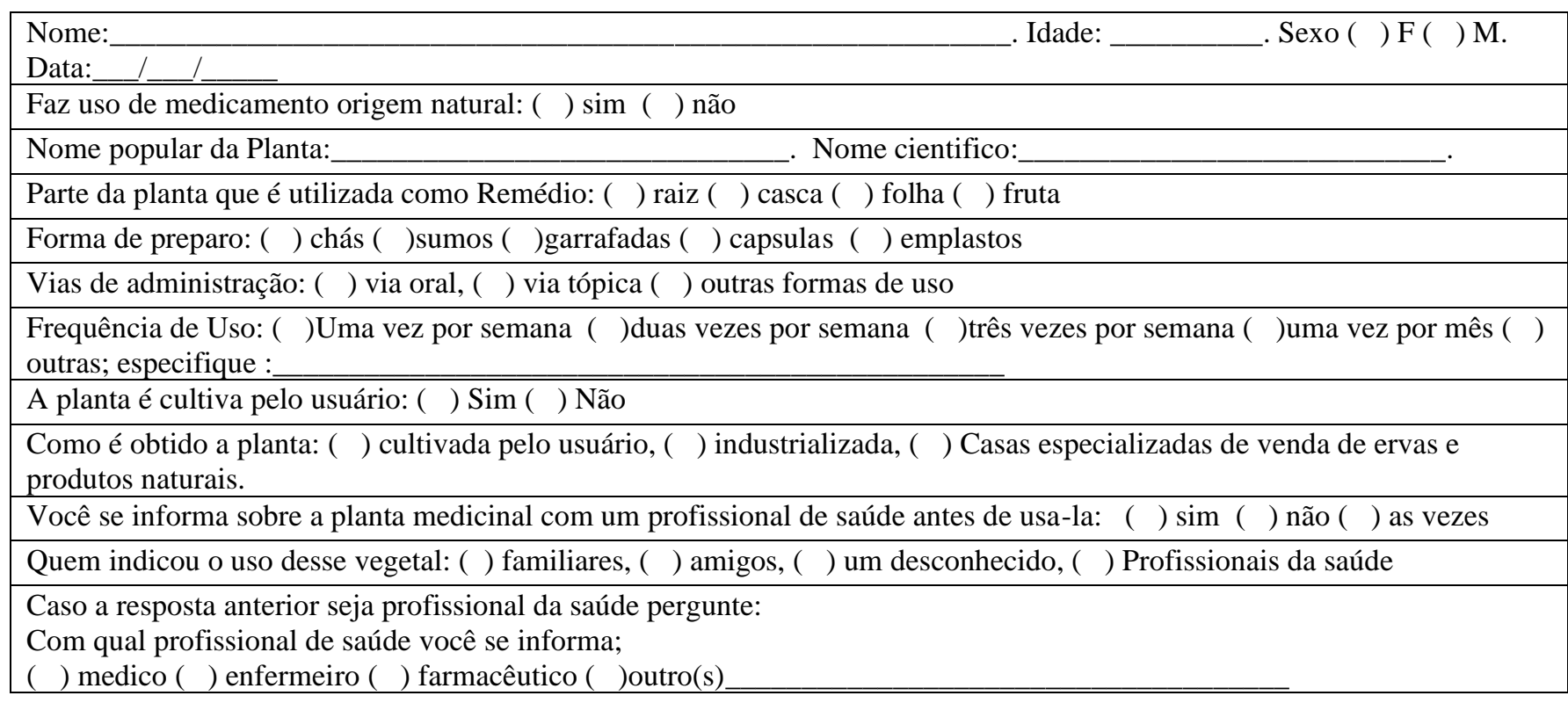

Fonte: Autores.

\section{Análise dos dados}

Inicialmente os dados foram convertidos em unidades relativa (percentual) para se ter uma melhor comparação por meio da unidade relativa ao total de entrevistados. Posteriormente no intuito de tornar mais clara a comparação entre as respostas obtidas os dados foram plotados em figuras e/ou apresentado em tabelas. Tendo em vista o elevado número de 
espécies citadas realizou-se uma seleção das 5 espécies mais citadas. Foi usado como critério de seleção as espécies que foram citadas como uma planta de uso terapêutico por mais de $5 \%$ dos entrevistados.

O Porcentual de Concordância de Uso Principal (CUP) indicou a importância relativa das plantas utilizadas pela população da cidade de Redenção. O qual foi calculada por meio da divisão do número de entrevistados que citaram o uso principal pelo número de entrevistados que citaram uso da espécie vegetal, seguido pela multiplicação do resultado por 100 (Silva et al, 2021).

\section{Resultados e Discussão}

Foram entrevistados 113 indivíduos, sendo 84,9\% mulheres e 15,1\% homens. A faixa etária dos entrevistados variou de 18 a 80 anos com média de idade de 40,75 anos. A predominância de entrevistados do sexo feminino também foi relatada por Gonçalves et al. (2018) em estudo etnobotânico do conhecimento e uso de plantas medicinais em Santa Luzia, Maranhão, Brasil, no qual observou que de 53 entrevistados 38 eram mulheres, ou seja, a grande maioria assim como os dados da presente pesquisa. Os mesmos autores ainda apresentam a média de idade dos entrevistados de 47 anos, valor médio aproximado do determinado no presente estudo. É valido ressaltar que apenas destes $17(15,1 \%)$ relataram que não fazerem uso de nenhum tipo de plantas medicinais, ou seja, 84,9\% fazem ou já fizeram uso de plantas medicinas para prevenção ou tratamento de alguma patologia. Resultado semelhante foi observado por, Vale et al. (2021) os quais constataram que 84\% dos participantes do estudo utilizam plantas medicinais como terapia alternativa ou complementar para prevenção e/ou tratamento de doenças ou sintomas destas. Isso mostra que mesmo com os avanços tecnológicos da indústria dos fármacos sintéticos, a utilização de plantas/ervas faz parte da cultura local.

Quanto as plantas citadas pelos entrevistados estão dispostas na Tabela 1, sendo apresentado seu nome popular, nome cientifico, porcentagem que é usada pelos entrevistados, a indicação e a porcentagem de uso para indicação conhecida.

Tabela 1. Nome popular, nomenclatura oficial, percentual de uso, indicação de uso e de concordância do uso principal das plantas citadas.

\begin{tabular}{|c|c|c|c|c|}
\hline Nome popular & $\begin{array}{l}\text { Nomenclatura } \\
\text { oficial }\end{array}$ & $\begin{array}{l}\text { Percentual } \\
\text { de uso }(\%)\end{array}$ & Indicação de uso & $\begin{array}{c}\text { Porcentual de } \\
\text { Concordância de } \\
\text { Uso Principal (\%) }\end{array}$ \\
\hline Cavalinha & Equisetum & 1,04 & $\begin{array}{c}\text { Diurético, anti-inflamatória, cicatrizante, } \\
\text { digestiva, hipoglicemiante, remineralizante, } \\
\text { hipotensora e antioxidante } \\
\text { hi, }\end{array}$ & 100,0 \\
\hline Babosa & Aloe vera & 0,53 & Atividade anti-inflamatória e cicatrizante 3,4 & 100,0 \\
\hline Crajiru, Pariri & $\begin{array}{l}\text { Arrabidaea } \\
\quad \text { chica }\end{array}$ & 1,06 & $\begin{array}{c}\text { Dores intestinais, diarreia e diarreia com sangue, } \\
\text { hemorragia, anemia,Icterícia, corrimento vaginal, } \\
\text { feridas na pele, inflamações ginecológicas e } \\
\text { conjuntivite }{ }^{5} \text {. }\end{array}$ & 50,0 \\
\hline Carqueja & $\begin{array}{l}\text { Baccharis } \\
\text { trimera }\end{array}$ & 0,53 & Anti-inflamatório e diurética ${ }^{3}$. & 100,0 \\
\hline Chá-da-índia & $\begin{array}{l}\text { Camellia } \\
\text { sinensis }\end{array}$ & 0,54 & Diurético ${ }^{6}$. & 100,0 \\
\hline $\begin{array}{l}\text { Cipó-puci, cortina- } \\
\text { de-pobre, insulina- } \\
\text { vegetal, uva-brava, }\end{array}$ & $\begin{array}{c}\text { Cissus } \\
\text { verticillata }\end{array}$ & 0,55 & $\begin{array}{l}\text { Antiflamatório, antiepilético, anti-hipertensivo, } \\
\text { antirreumático e antidiabético }{ }^{3}\end{array}$ & 100,0 \\
\hline
\end{tabular}




\begin{tabular}{|c|c|c|c|c|}
\hline Nome popular & $\begin{array}{l}\text { Nomenclatura } \\
\text { oficial }\end{array}$ & $\begin{array}{l}\text { Percentual } \\
\text { de uso }(\%)\end{array}$ & Indicação de uso & $\begin{array}{l}\text { Porcentual de } \\
\text { Concordância de } \\
\text { Uso Principal (\%) }\end{array}$ \\
\hline Limão siciliano & Citrus limonum & 0,56 & $\begin{array}{l}\text { Adstringente, alcalinizante, antianémica, } \\
\text { antibiótica, antidepressiva, antiemética, } \\
\text { antiescorbútica, antiespasmódica, } \\
\text { antiinflamatória, anti-séptica, antitérmica, } \\
\text { aperiente, bactericida, clareador da pele, } \\
\text { depurativa, diaforética, diurético, expectorante, } \\
\text { refrescante, sedativa, sudorífera, tônica } \\
\text { estomacal, vermífuga, vitaminizante }\end{array}$ & 100,0 \\
\hline $\begin{array}{l}\text { Algodão-do- } \\
\text { campo,algodãozinho }\end{array}$ & $\begin{array}{l}\text { Cochlospermum } \\
\text { insigne }\end{array}$ & 0,56 & $\begin{array}{l}\text { Atividades hepatoprotetoras, analgésica, anti- } \\
\text { edematogênica, anti-bacteriana, antioxidante, } \\
\text { mutagênica, citotóxica, antinociceptiva }{ }^{7} \text {. }\end{array}$ & 100,0 \\
\hline Açafrão da terra & Curcuma longa & 0,56 & Antiflamatório e antioxidante ${ }^{3}$. & 100,0 \\
\hline Capim cidreira & $\begin{array}{l}\text { Cymbopogon } \\
\text { citratus }\end{array}$ & 10,73 & $\begin{array}{l}\text { Analgésico, calmante, problemas estomacais, } \\
\text { hipertensão, antipirético e estimulante lácteo }{ }^{1,2} \text {. }\end{array}$ & 100,0 \\
\hline $\begin{array}{l}\text { Matruz, Erava de } \\
\quad \text { Santa M }\end{array}$ & $\begin{array}{l}\text { Dysphania } \\
\text { ambrosioides }\end{array}$ & 3,16 & $\begin{array}{l}\text { Vermífugo, aumento da imunidade, anti- } \\
\text { inflamatório, anti-hipertensivo, problemas } \\
\text { digestórios, antibiótico }{ }^{1,2} \text {. }\end{array}$ & 100,0 \\
\hline $\begin{array}{l}\text { Caruru-azedo, } \\
\text { azedinha }\end{array}$ & $\begin{array}{l}\text { Hibiscus } \\
\text { sabdariffa }\end{array}$ & 0,66 & $\begin{array}{l}\text { Dispepsias hiposecretoras, disquinesias } \\
\text { hepatobiliares, gastroenterites, } \\
\text { hipertensão,resfriados e gripes }{ }^{4} \text {. }\end{array}$ & 100,0 \\
\hline Camomila & $\begin{array}{l}\text { Matricaria } \\
\text { chamomilla }\end{array}$ & 0,66 & $\begin{array}{l}\text { Anti-inflamatória, antisséptica, antiespasmódica } \\
\qquad \text { e calmante }^{3} \text {. }\end{array}$ & 100,0 \\
\hline Erva-cidreira & $\begin{array}{l}\text { Melissa } \\
\text { officinalis }\end{array}$ & 4,67 & Gastroenterites, calmante e ansiolítico ${ }^{1}$. & 100,0 \\
\hline Poejo & $\begin{array}{l}\text { Mentha } \\
\text { pulegium }\end{array}$ & 2,10 & $\begin{array}{c}\text { Antitussígeno, antiespasmódico, antitérmico e } \\
\text { analgésico }^{3} \text {. }\end{array}$ & 100,0 \\
\hline Hortelã & Mentha spicato & 5,00 & Expectorante, calmante e problemas intestinais ${ }^{1}$. & 85.71 \\
\hline Manjericão & $\begin{array}{c}\text { Ocimum } \\
\text { basilicum }\end{array}$ & 0,76 & $\begin{array}{c}\text { Analgésica, antiemético, antipirético, } \\
\text { antisséptico, expectorante }{ }^{3} \text {. }\end{array}$ & 100,0 \\
\hline Maracujá & $\begin{array}{l}\text { Passiflora } \\
\text { incarnata }\end{array}$ & 0,77 & Calmante ${ }^{4}$. & 100,0 \\
\hline Ora-pro-nóbis & $\begin{array}{l}\text { Pereskia } \\
\text { aculeata }\end{array}$ & 0,78 & Auxilio do sistema digestivo ${ }^{4}$. & 100,0 \\
\hline Erva-doce & $\begin{array}{l}\text { Pimpinella } \\
\text { anisum }\end{array}$ & 1,56 & $\begin{array}{l}\text { Calmante, antiespasmódico, gastroenterites, } \\
\text { estimulante geral, galactogogo e diurético }{ }^{1,3} \text {. }\end{array}$ & 100,0 \\
\hline Boldo de Jardim & $\begin{array}{l}\text { Plectranthus } \\
\text { barbatus }\end{array}$ & 2,38 & Problemas Intestinais ${ }^{3}$. & 100,0 \\
\hline $\begin{array}{l}\text { Boldo-do-chile, } \\
\text { boldo-verdadeiro }\end{array}$ & Pneumus boldus & 10,57 & Distúrbios gastrointestinais ${ }^{1}$. & 100,0 \\
\hline Sucupira & $\begin{array}{l}\text { Pterodon } \\
\text { emarginatus }\end{array}$ & 0,91 & $\begin{array}{c}\text { Antirreumáticas, analgésicas, antimicrobiana, } \\
\text { anti-inflamatória }{ }^{2} .\end{array}$ & 100,0 \\
\hline Romã & $\begin{array}{l}\text { Punica } \\
\text { granatum }\end{array}$ & 0,92 & Antisséptico e anti-inflamatório ${ }^{3}$. & 100,0 \\
\hline Alecrim & $\begin{array}{l}\text { Palvia } \\
\text { rosmarinus }\end{array}$ & 4,63 & Anti-inflamatório, problemas gastrointestinais ${ }^{2}$. & 40,0 \\
\hline Gervão & $\begin{array}{l}\text { Stachytarpheta } \\
\text { cayennensis }\end{array}$ & 0,98 & Anti-inflamatório e analgésico ${ }^{3}$. & 100,0 \\
\hline Valeriana & $\begin{array}{l}\text { Valeriana } \\
\text { officinalis }\end{array}$ & 2,04 & Calmante, sedativo leve ${ }^{1}$. & 100,0 \\
\hline
\end{tabular}

Nota: ${ }^{1}$ (Alencar et al., 2019), ${ }^{2}$ (Badke, Budó, Silva, \& Ressel, 2011), ${ }^{3}$ (Gonçalves et al., 2017), ${ }^{4}$ (Humenhuk, Leite, \& Fritsch, 2020), ${ }^{5}$ (Barros, 2018), ${ }^{6}$ (Senger, Schwanke, \& Valle, 2010), ${ }^{7}$ (CNCFlora, 2012). Fonte: Autores. 
Foram citadas 27 plantas pelos entrevistados. Observando a Tabela 1 torna-se evidente que a população entrevistada possui o conhecimento sobre a finalidade para a qual a planta tem seu uso recomendado, e fazem seu uso adequadamente. Tendo em vista que dentre as 27 citadas 24 delas obtiveram de concordância de uso principal com o uso citado pelos entrevistados.

Foi realizado uma seleção para se destacar as espécies que foram citadas por pelo menos $5 \%$ da população como apresentado na Figura 1. Observe que as cinco mais citadas foram Capim cidreira (Cymbopogon citratus) 20,83\%, Boldo-dochile, boldo-verdadeiro (Ppneumus boldus) 13,54\%, Erva-cidreira (Melissa officinalis) 6,25\%, Hortelã (Mmentha spiccato) 7,29\% e Matruz, Erva de Santa Maria (Ddysphania ambrosioides) 5,20\%.

Figura 1. Representação das plantas mais citadas pelos entrevistados.

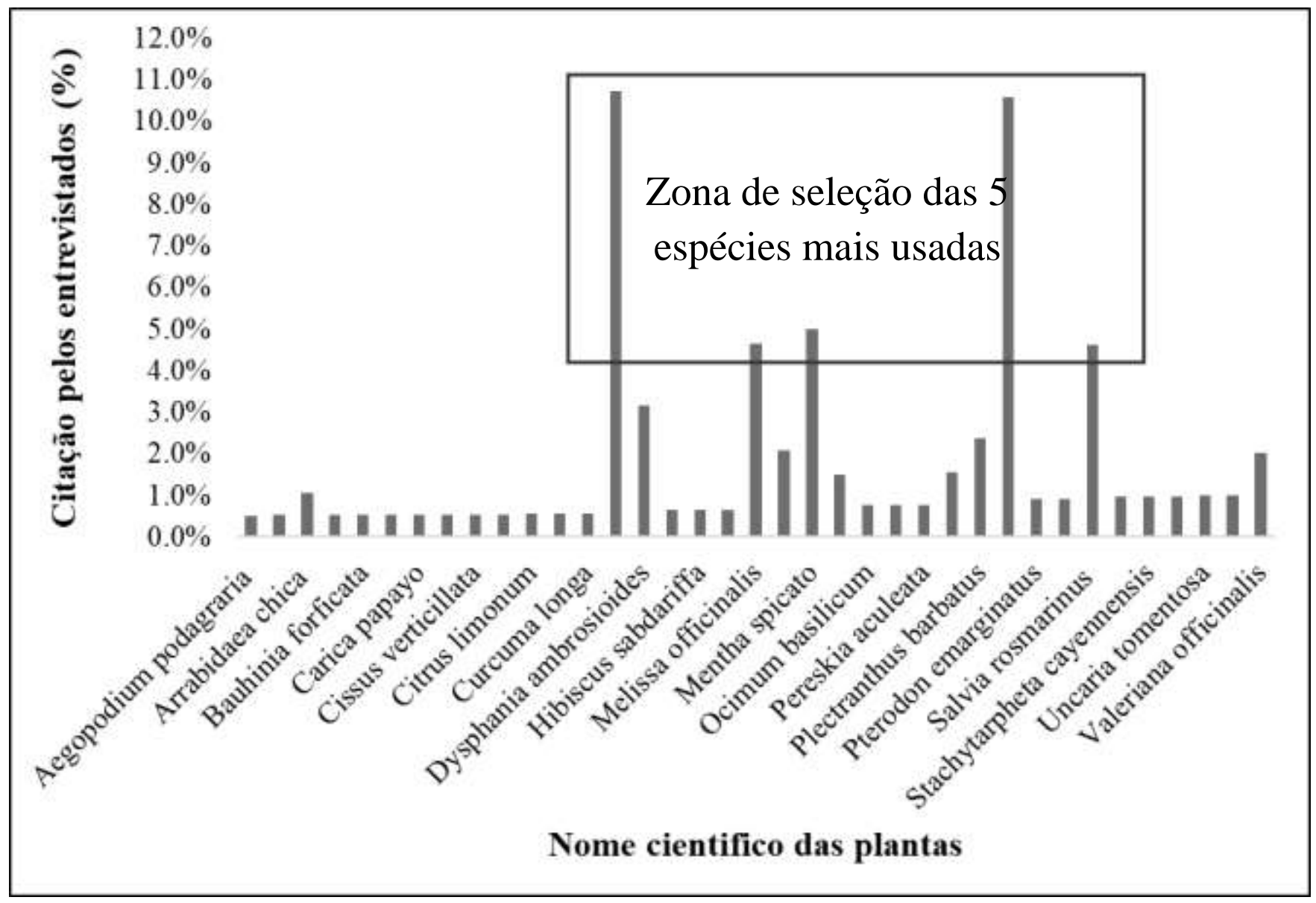

Fonte: Autores.

Quanto a funcionalidade destas, os participantes utilizam tanto o Capim cidreira (Cymbopogon citratus) como a ervacidreira (Melissa officinalis) tem seu uso principal reconhecido e recomendado como calmante natural. Oliveira \& Santos (2021), concluem que as ações terapêuticas apresentadas pelo capim cidreira são produzidas, principalmente, pela presença do citral, componente em maior quantidade no óleo essencial desta erva. Buzin et al., (2021) realizaram um estudo com a finalidade de verificar a utilização de plantas medicinais como fins calmantes, por parte dos usuários das Unidades Básicas de Saúde (UBS) que trabalham com Estratégia Saúde da Família (ESF) no município de Toledo/PR. Em seus estudos também contataram que as plantas citadas anteriormente são utilizadas como calmante natural.

As folhas do capim cidreira são bastante utilizadas, sob a forma de infusão, como sedativo e calmante do sistema nervoso. Estudos confirmam sua eficiência antiespasmódica, analgésica, bactericida, inseticida, inibitória do crescimento de 
fungos e antimutagênica (Brito, Garruti, Alves \& Blank, 2011). E a erva cidreira contêm elevadas quantidades de citral, limoneno e mirceno além da carvona, os quais possui ação comprovada no combate a dor, inflamação e atividade ansiolítica relatados em estudos pré-clínicos. A Melissa oficinalles tem como principal indicação, a atuação sedativa, analgésica, antiespasmódica e ansiolítica (Saad, Oliveira, Sá \& Seixiack, 2016).

Lins et al., (2015) quantificaram os compostos bioativos presentes nas espécies de erva cidreira (Melissa officinalis L.) e capim cidreira (Cymbopogon citratus (DC) Stapf), comercializados na feira livre de Campina Grande e analisaram as amostras no Laboratório de Engenharia de Alimentos da Universidade Federal de Campina Grande. Verificaram que ambas as plantas apresentam quantidades significativas de compostos bioativos, o que podem comprovar os seus potenciais terapêuticos.

O uso do boldo-do-chile, boldo-verdadeiro (Pneumus boldus) pelos participantes da pesquisa, se dá para fins de tratamento de moléstias intestinais e hepáticas. Os resultados obtidos no estudo de Silva (2016) apresentaram que a espécie vegetal Peumus boldus demonstrou ser capaz de modular o metabolismo lipídico nas células hepáticas estreladas inclusive em nível de expressão de genes, o que suporta o uso popular dessa planta quando da ingestão de alimentos gordurosos. Gontijo, Borges, Pires, Figueiredo e Arruda, (2019) analisaram as propriedades bioativas do composto boldina presente no Peumus boldus e a toxicidade do mesmo utilizando métodos in silico. Verificaram que por meio da boldina, seu principal composto, a planta possui boa atividade e estimulante de liberação de serotonina. Mostrando relevante eficiência no controle da motilidade gastrointestinal e manutenção de processos inflamatórios do organismo.

Já a hortelã (Mentha spiccato) foi citada para tratamento de gripes e resfriados. Mahboubi, (2021) relata que esta vem sendo usada como aperitivo e planta medicinal desde as civilizações greco-romanas. É indicada para tratamento de resfriados e gripes, dor de garganta, rinite alérgica, asma brônquica, bronquite e sinusite (Suzuki, Barone, Ranucci \& Martins, 2020). A carvona é o composto mais notável presente na planta, sendo ele o responsável por conferir à planta seu aroma característico. Outro composto é o ácido rosmarínico, que é um antioxidante polifenólico com atividades imunossupressoras, antiinflamatórias, antibacterianas e antivirais (Lasrado et al., 2017).

O Matruz, Erva de Santa Maria (Dysphania ambrosioides) foi citada com atuação como anti-inflamatório e antibiótico. Sérvio et al. (2011) verificaram a cicatrização de feridas abertas em ratos após a utilização do extrato de mastruz com ou sem cobertura secundária estéril de gaze por meio de análise morfométrica e histológica. Os resultados apontaram que, no intervalo de quatro dias, foi constada maior contração da ferida no grupo tratado apenas com utilização do mastruz em relação aos demais grupos e evidências histológicas de amadurecimento do tecido de granulação com deposição de colágeno. Constatou-se que o extrato aquoso do mastruz contribuiu para a cicatrização de feridas cutâneas abertas em ratos.

Outra ação importante advinda do mastruz é a antipasitária. Esta foi relatada pela primeira vez na literatura européia no século XVIII, quando o botânico sueco Peter Kalm relata o uso da planta pelos nativos e europeus nas colônias americanas para eliminação do verme intestinal Ascaris sp. Provavelmente essa seja a planta mais conhecida pelos indígenas americanos com propriedade anti-helmíntica (Sá, Soares \& Randau, 2015). Santos et al. (2016) realizaram um levantamento das plantas indicadas na medicina tradicional em uma aldeia indígena na região Nordeste do Brasil, utilizadas para o tratamento de doenças causadas por parasitos gastrointestinais. Nesse estudo o mastruz foi uma das plantas mais citadas, sendo utilizado suas folhas em forma de chá.

É possível observar que as pessoas entrevistadas faziam uso das plantas para a finalidade a qual a mesma é conhecida (Tabela 1). Quanto a indicação para utilização das plantas como meio de tratamento, os entrevistados apresentaram a família como sendo quem mais indica o uso das plantas 81,36 \%. O fato de que a maioria da população segue indicação de familiares também foi constado no estudo realizado por Ribeiro, Valliatti, Barcelos e Goulart, (2020) no qual avaliaram o conhecimento e o perfil de utilização de plantas medicinais pela população do município de Presidente Médici-RO. No qual constataram que entre os entrevistados nesse estudo 52\% obtiveram informações a respeito de plantas medicinais com seus familiares. Esse 
conhecimento passado de geração para geração é de grande relevância, pois demonstra que parte da cultura se manteve preservada. Observa-se que os entrevistados utilizam as plantas para sua devida finalidade. No entanto, ainda é necessário que a população obtenha conhecimento sobre os possíveis riscos da utilização incorreta de plantas medicinais, como as interações planta-planta e entre planta-medicamento.

Seguido a indicação pelos familiares tem-se a da indicação por amigos 19 (21,44\%), posteriormente os profissionais de saúde e desconhecidos 2 (2,26 \%). Apesar de terem sido aprovadas, em 2006, a Política Nacional de Praticas Integrativas e Complementares (PNPIC) e a Política Nacional de Plantas Medicinais e Fitoterápicos (PNPMF), são raros os exemplos de prescrições e/ou indicação do uso de plantas medicinais ou outra terapia complementar e orientações sobre a utilização dessa prática por profissionais da saúde, o que provavelmente se dá pela falta desse debate no decorrer da formação desses profissionais (Siqueira, Ceolin, Minuto, Oliveira \& Leal, 2017). Pôr fim tem-se a internet 1 (1,13 \%), como apresentado na Figura 2.

Figura 2. Porcentagem de indicação para uso das plantas como meio de tratamento medicinal.

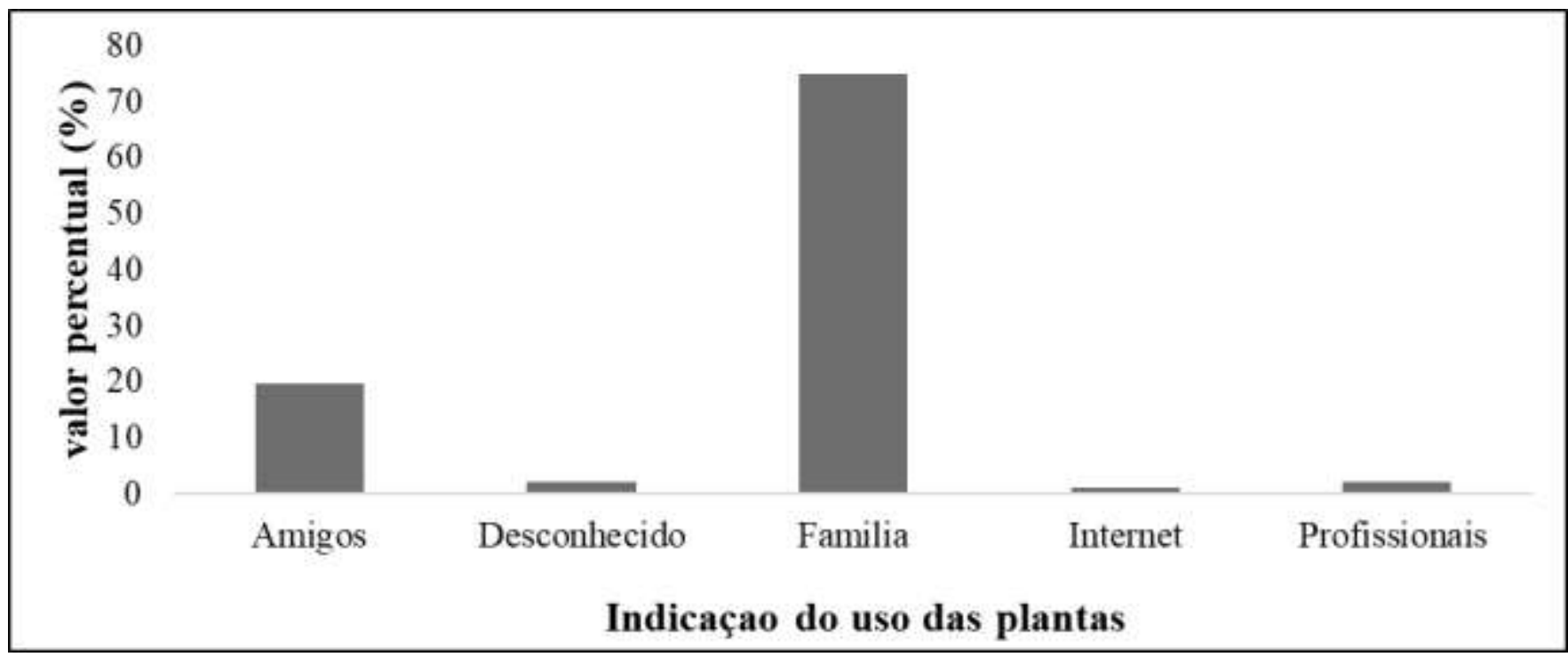

Fonte: Autores.

Pode-se observar na Figura 3, as porcentagens referentes a forma de preparação das plantas para o consumo, $70 \%$ dos entrevistados as preparam como chás, $20 \%$ se utilizam do sumo, $2 \%$ em forma de garrafadas e $1 \%$ em cápsulas.

Resultado semelhante fio obtido no estudo de Oliveira, Mezzomo e Moraes, (2018) onde os mesmos avaliaram o conhecimento e o uso de plantas medicinais pela população frequentadora de Unidades Básicas de Saúde em Colombo, PR. Neste $69,53 \%$ dos entrevistados preparavam as plantas como chás. No estudo feito por Szerwieski, Cortez, Silva e Ranieri, (2017) 74,72\% dos entrevistados também relataram o uso do chá como forma de preparação das plantas. Santos et al., (2018), relata que o chá é a segunda bebida mais consumida no mundo. Esse fato pode interferir positivamente para que seja usado essa forma de preparo para plantas medicinais, tendo em vista que é uma técnica milenar de conhecimento de maioria da população mundial. 
Figura 3. Forma de preparo das plantas medicinais citadas pelos entrevistados.

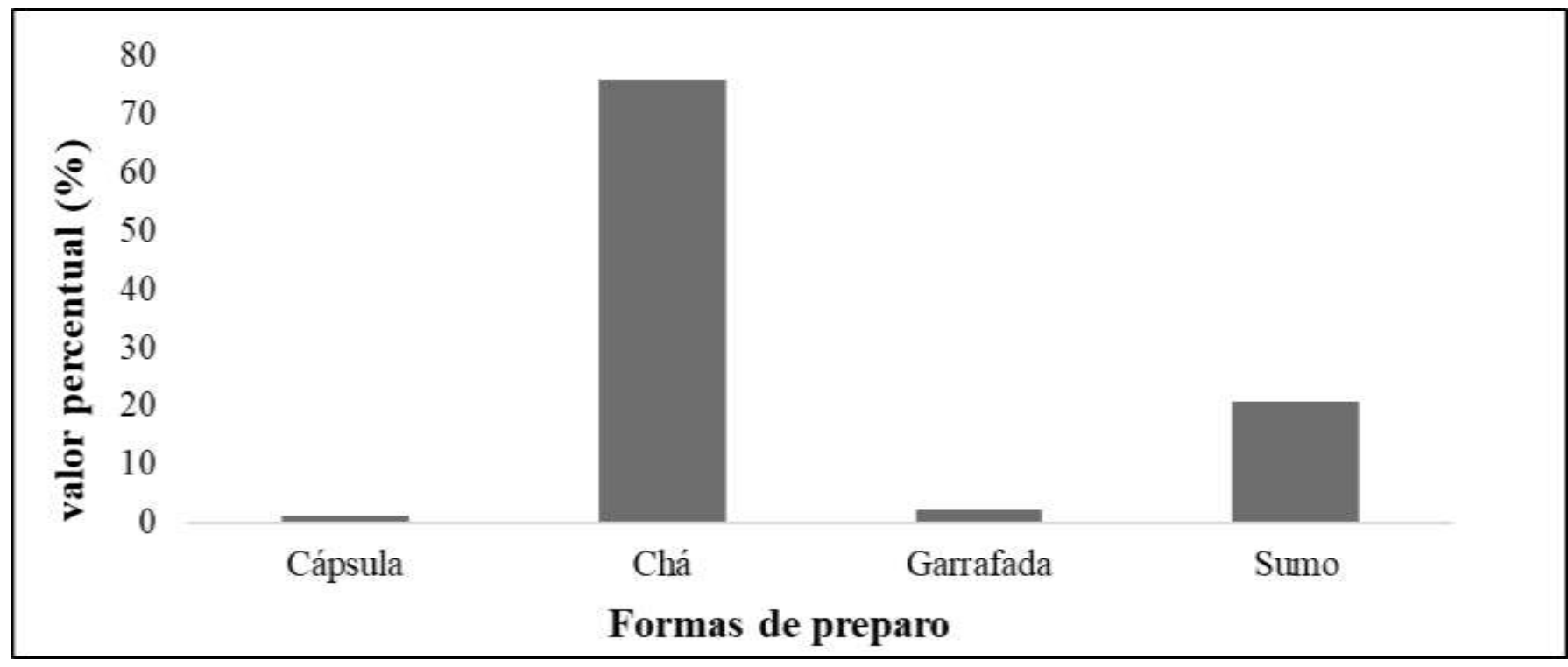

Fonte: Autores.

Observando a Figura 4 é possível verifica-se que a parte das plantas mais utilizadas são as folhas, sendo citadas por 82, 29\% dos entrevistados. É provável que o favoritismo pelo uso das folhas aconteça, pela facilidade de coleta em relação às partes subterrâneas ou os frutos. As folhas também estão disponíveis em as estações do ano e por serem ativas fotossinteticamente, ocorre produção de metabólitos secundários (Leal et al., 2019).

Figura 4. Partes utilizadas das plantas.

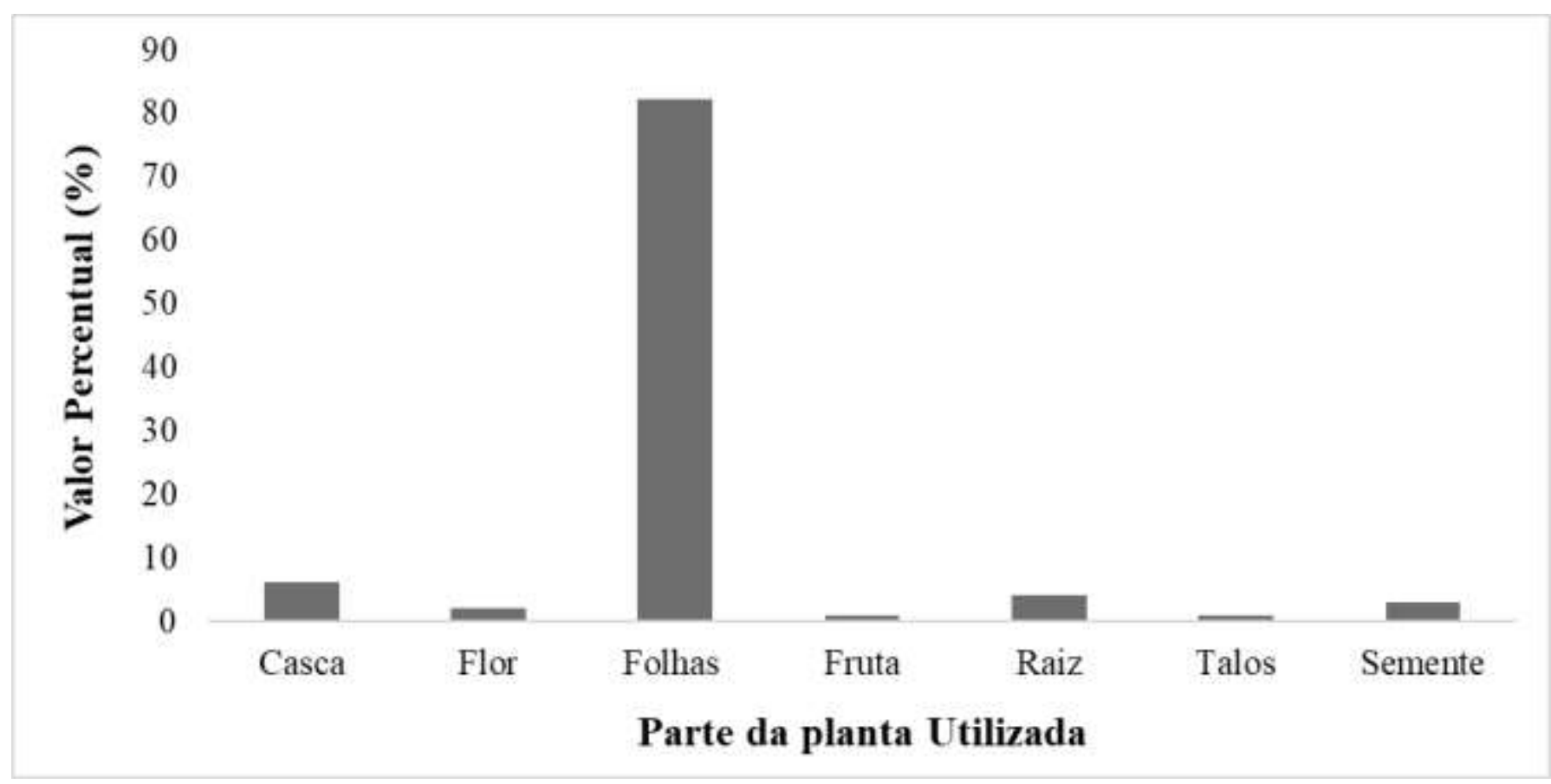

Fonte: Autores.

Oliveira e Lucena, (2015) em seu estudo sobre o uso de plantas medicinais por moradores de Quixadá-Ceará, também relatam que as partes das plantas utilizadas pelos entrevistados foram principalmente as folhas, representando $89,4 \%$ dos relatos. O mesmo foi verificado por Almeida, Barros e silva, (2015), em seu levantamento das plantas utilizadas como recurso 
terapêutico, suas partes e as formas de uso, bem como a existência de consenso entre os informantes para tratamentos específicos em duas comunidades rurais da Serra do Passa-Tempo, município de Campo Maior, estado do Piauí.

\section{Considerações Finais}

A presente pesquisa permitiu apresentar o conhecimento tradicional e empírico dos, habitantes da cidade de Redenção localizada na região sul Paraense, a respeito do uso das plantas medicinais. Constatou-se que os entrevistados, de modo geral, afirmam fazer uso das espécies medicinais e que a em sua maioria o fazem da forma correta. Observou-se, também que a principal forma de transmissão de conhecimento é por meio da família. Nesta pesquisa ficou evidente, que as plantas mais utilizadas pelos moradores desta cidade são Capim cidreira, Boldo-do-chile ou boldo-verdadeiro, Erva-cidreira, Hortelã e Matruz ou Erva de Santa Maria, sendo as folhas a parte mais utilizada e o chá como principal meio de preparo.

\section{Referências}

Alencar, M. E., Cajaiba, R. L., Martins, J. D. S. C., Cordeiro, R. S., Sousa, E. S., \& Almeida, S. V. (2019). Estudo etnobotânico do conhecimento e uso das plantas medicinais no município de Buriticupu, Maranhão, Brasil. Revista Ibero-Americana de Ciências Ambientais, 10(6), 328-338. https://doi.org/10 .6008/CBPC2179-6858.2019.006.0028

Almeida, N. J. R., de Barros, R. F. M., \& Silva, P. R. R. (2015). Uso de plantas medicinais em comunidades rurais da Serra do Passa-Tempo, estado do Piauí, Nordeste do Brasil. Revista brasileira de biociências, 13(3), 165-175. http://www.ufrgs.br/seerbio/ojs/index.php/rbb/article/view/3280

Badke, M. R., Budó, M. D. L. D., Silva, F. M. D., \& Ressel, L. B. (2011). Plantas medicinais: o saber sustentado na prática do cotidiano popular. Escola Anna Nery, 15(1), 132-139. https://doi.org/10.1590/S1414-81452011000100019

Barros, A. S. M. (2018). Investigação científica da atividade medicinal da espécie Arrabidaea chica (Pariri). Monografia (Licenciatura em ciências naturais Biologia) - Universidade Federal do Maranhão, Pinheiro - MA. https://monografias.ufma.br/jspui/bitstream/123456789/3224/1/AURENI-BARROS.pdf

Brito, E. S., Garruti, D. D. S., Alves, P. B., \& Blank, A. F. (2011). Caracterização odorífera dos componetes do óleo essencial de capim-santo (Cymbopogon citratus (DC.) stapf., Poaceae) por cromatografia gasosa (CG)-olfatometria. Embrapa Agroindústria Tropical-Boletim de Pesquisa e Desenvolvimento (INFOTECA-E), Fortaleza - CE. https://www.infoteca.cnptia.embrapa.br/bitstream/doc/900884/1/BPD11001.pdf

Buzin, G., Souza, L. P., Alencar, Q. H. O., Santos, M. B., Andrade, S. M., \& Teixeira, K. N. Plantas Usadas Como Calmante Natural Em Unidades Básicas De Saúde De Toledo/PR. Varia Scientia-Ciências da Saúde, 7(1), 18-31.

CNCFlora. Centro Nacional de Conservação da Flora (2012). Cochlospermum regium (Mart. ex Schrank) Pilg. http://www.cncflora.jbrj.gov.br/portal/ptbr/profile/Cochlospermum\%20regium.

Costa, V. P., \& Mayworm, M. A. S. (2011). Plantas medicinais utilizadas pela comunidade do bairro dos Tenentes-município de Extrema, MG, Brasil. Revista Brasileira de Plantas Medicinais, 13(3), 282-292. https://www.scielo.br/j/rbpm/a/kSZ67JWPzpnLpkRt6VxhSbN/?format=pdf\&lang=pt

Duarte, A. F. S., da Costa Martins, A. L., Miguel, M. D., \& Miguel, O. G. (2018). O uso de plantas medicinais durante a gravidez e amamentação. Visão Acadêmica, 18(4) 126-139. http://dx.doi.org/10.5380/acd.v18i4.55983

Gonçalves, M. D. M. M., Cajaiba, R. L., Santos, W. B., Sousa, E. S., Martins, J. D. S. C., Pereira, K. S., \& Almeida. S. V. (2018). Estudo etnobotânico do conhecimento e uso de plantas medicinais em Santa Luzia, Maranhão, Brasil. Revista Ibero-Americana de Ciências Ambientais, 9(5), 12-21. https://doi.org/10.6008/CBPC2179-6858.2018.005.0002

Gontijo, L., Borges, A. M., Pires, M. L. O., Figueiredo, N. P., \& Arruda, E. L. (2019). PREDIÇÃO DAS PROPRIEDADES DO COMPOSTO BOLDINA ENCONTRADO EM PEUMUS BOLDUS. In Congresso Interdisciplinar-ISSN: 2595-7732. http://anais.unievangelica.edu.br/index.php/cifaeg/issue/view/124

Humenhuk, T., Leite, D. R. B., \& Fritsch, M. (2020). Conhecimento popular sobre plantas medicinais utilizadas no município de Mafra, SC, Brasil. Saúde e meio ambiente: revista interdisciplinar, 9, 27-42. https://doi.org/10.24302/sma.v9i0.2466

Lasrado, J. A., Nieman, K. M., Fonseca, B. A., Sanoshy, K. D., Schild, A. L., \& Herrlinger, K. A. (2017). Safety and tolerability of a dried aqueous spearmint extract. Regulatory Toxicology and Pharmacology, 86, 167-176. https://doi.org/10.1016/j.yrtph.2017.03.005

Leal, J. B., da Silva, M. M., Costa, J. M., de Albuquerque, L. C. D. S., Pereira, M. S. D. G., \& Sousa, R. L. (2019). Etnobotânica de plantas medicinais com potencial anti-inflamatório utilizadas pelos moradores de duas comunidades no município de Abaetetuba, Pará. Biodiversidade, 18(3), 110-125. file://C:/Users/u1009280/Downloads/9410-Texto\%20do\%20Artigo-33454-1-10-20191123\%20(1).pdf

Lins, A. D. F., Oliveira, M. N., Fernandes, V. O., Rocha, A. P. T., Sousa, F. C., Martins, A. N. A., \& Nunes, E. N. (2015). Quantificação de compostos bioativos em erva cidreira (Melissa officinalis L.) e capim cidreira [Cymbopogon citratus (dc) Stapf.]. Gaia Scientia, 9(1), 17-21.

MahboubI, M. (2021). Óleo essencial de Mentha spicata L., fitoquímica e sua eficácia na flatulência. Journal of Traditional and Complementary Medicine, 11(2), 75-81. https://doi.org/10.1016/j.jtcme.2017.08.011. 
Oliveira, C. C. A. de., \& Santos, J. S. (2021). Active compounds of lemon grass (Cymbopogon citratus): a review. Research, Society and Development, 10(12), e263101220281. https://doi.org/10.33448/rsd-v10i12.20281

Oliveira, D. S., \& Lucena, E. M. P. (2015). O uso de plantas medicinais por moradores de Quixadá-Ceará. Revista Brasileira de Plantas Medicinais, 17, 407412. https://doi.org/10.1590/1983-084X/13_095

Oliveira, V. B. D., Mezzomo, T. R., \& Moraes, E. F. D. (2018). Conhecimento e uso de plantas medicinais por usuários de unidades básicas de saúde na região de Colombo, PR. Revista Brasileira de Ciências da Saúde, 22(1), 57-64. https://doi.org/10.4034/RBCS.2018.22.01.08

Ribeiro, A. F., Valiatti, T. B., Barcelos, I. B., \& Goulart, R. R. (2020). Uso de plantas medicinais pela população do município de Presidente Médici, Rondônia, Brasil. Revista Saúde e Desenvolvimento, 14(19). https://www.revistasuninter.com/revistasaude/index.php/saudeDes envolvimento/article/view/1122

Sá, R. D., Soares, L. A. L., \& Randau, K. P. (2015). Óleo essencial de Chenopodium ambrosioides L.: estado da arte. Revista de Ciências Farmacêuticas Básica e Aplicada, 36(2). http://rcfba.fcfar.unesp.br/index.php/ojs/article/view/40/39

Saad, G. D. A., Léda, P. H. D. O., Sá, I. D., \& Seixlack, A. C. C. (2016). Fitoterapia contemporânea: tradição e ciência na prática clínica, 2 , 245.

Santos, V. P., \& Trindade, L. M. P. (2017). A enfermagem no uso das plantas medicinais e da fitoterapia com ênfase na saúde pública. Revista Científica FacMais, 8(1), 16-34. https://revistacientifica.facmais.com.br/wp-content/uploads/2017/04/A-ENFERMAGEM-NO-USO-DAS-PLANTAS-MEDICINAIS-EDA-FITOTERAPIA-COM-\%C3\%8ANFASE-NA-SA\%C3\%9ADE-P\%C3\%9ABLICA-1.pdf

Santos. L. T. M., Santos, D. R. V., Souza, R. M., Bastos, N. G., Vannier-Santos, M. A., Nunes, E. S., \& Dias-Lima, A. G. (2016). Plantas medicinais com ação antiparasitária: conhecimento tradicional na etnia Kantaruré, aldeia Baixa das Pedras, Bahia, Brasil. Revista brasileira de plantas medicinais, $18,240-247$. https://doi.org/10.1590/1983-084X/15_063

Senger, A. E. V., Schwanke, C. H., \& Gottlieb, M. G. V. (2010). Chá verde (Camellia sinensis) e suas propriedades funcionais nas doenças crônicas não transmissíveis. Scientia Medica, 20(4), 292-300.

Sérvio, E. M. L., Araújo, K. S., Silva, N.L. R., da Costa, C. L. S., Mendes, L. M. S., Maia, F. A. L. M., \& Santos, Í. M. S. P. (2011). Cicatrização de feridas com a utilização do extrato de Chenopodium ambrosioides (mastruz) e cobertura secundária estéril de gaze em ratos. ConScientiae Saúde, 10(3), 441-448. https://doi.org/10.5585/conssaude.v10i3.2664

Silva, A. F. da, Sousa, R. L. de, Silva, S. G., Costa, J. M., Albuquerque, L. C. da S. de, Pereira, M. das G. da S., Mesquita, S. dos S., Silva, E. C. da, \& Cordeiro, Y. E. M. (2021). Ethnobotany of aromatic medicinal plants: preparations and uses of local flora in five rural communities located in the region of Baixo Tocantins, Pará, Brazil. Research, Society and Development, 10(1), e9510111284. https://doi.org/10.33448/rsd-v10i1.11284

Silva, C. M. D. (2016). Uso potencial de extrato de planta medicinal na reversão do processo fibrosante em células estreladas hepáticas. Trabalho de conclusão de curso (tcc) em Ecologia - Universidade Estadual Paulista, Instituto de Biociências de Rio Claro, Rio Claro - SP. https://repositorio.unesp.br/handle/11449/155832

Siqueira, V. J. B., Ceolin, T., Minuto, J. C., Oliveira, S. G., \& LEAL, A. D. O. (2017). Uso de plantas medicinais por hipertensos e diabéticos de uma estratégia saúde da família rural. Revista Contexto \& Saúde, 17(32), 33-45. https://doi.org/10.21527/2176-7114.2017.32.33-45

Souza, J. B. P., Ataliba, F. J. B., Costa, D. A., \& Farias, A. D. (2017). Interações planta medicinal x medicamento convencional no tratamento da hipertensão arterial. Infarma Ciências Farmacêuticas, 29(2), 90-9. https://pdfs.semanticscholar.org/2d22/9c9cea5e4c5aadc29c9177db04bb85671e8b.pdf

Suzuki, A. L. M., Baroni, C., Ranucci, J. S. T., \& Martins, L. A. (2020). Cartilha de plantas medicinais: indicadas para alívio de sintomas respiratórios. https://www.lume.ufrgs.br/bitstream/handle/10183/213547/001118066.pdf?sequence=1

Szerwieski, L. L. D., Cortez, D. A. G., Bennemann, R. M., Silva, E. S., \& Ranieri, L. E. C. (2017). Uso de plantas medicinais por idosos da atenção primária. Revista eletrônica de enfermagem, 19. https://doi.org/10.5216/ree.v19.42009 